DOI:

\title{
Dinamik Model Algoritması ile 1500 V DC Beslemeli Bir Metro Hattında Katener Kısa Devre Durumunun Analizi
}

\author{
Mehmet Taciddin AKÇAY ${ }^{1 *}$, İlhan KOCAARSLAN ${ }^{2}$
}

${ }^{1}$ Istanbul Metropolitian Municipality, Directorate of Rail Systems, Istanbul, Turkey ${ }^{1}$ ORCID ID: orcid.org/0000-0002-1050-4566

${ }^{2}$ Department of Electrical-Elektronics Engineering, Faculty of Engineering, Istanbul University, Istanbul, Turkey

ORCID ID: orcid.org/0000-0003-2591-4047

Geliş Tarihi: 30.05 .2019

*Sorumlu Yazar e mail: taciddin.akcay@ibb.gov.tr Kabul Tarihi: 23.09 .2019

Atıf/Citation: Akçay, M.T. ve Kocaarslan, İ. "Dinamik Model Algoritması ile 1500 V DC Beslemeli Bir Metro Hattında Katener Kısa Devre Durumunun Analizi”, Haliç Üniversitesi Fen Bilimleri Dergisi 2019, 2/2: $143-160$.

Araştırma Makalesi/ Research Article

\section{Özet}

Ulaşım sistemleri içinde elektrik beslemeli demiryolları yatırım tercihi olarak yüksek bir orana sahiptir. Elektrikli demiryollarında ise elektrifikasyon sisteminin elektrik verme görevini kusursuz olarak yerine getirebilmesi işletme sürekliliği için esastır. Tasarım öncesinde elektrifikasyon sistemi benzetimi yapılarak sisteme ait kapasite, performans ve arıza durumları test edilmektedir. İşletme sürekliliği için arıza durumlarının analizi ve olası tedbirlerin alınması büyük önem taşımaktadır. Bu çalışmada dinamik bir model oluşturularak $1500 \mathrm{~V}$ DC beslemeli bir şehiriçi metro hattının benzetimi yapılmıştır. Dinamik yapı için geliştirilen algoritma anlatılarak benzetim sonuçları verilmiştir. Çalışma için katener sisteminde olası bir kısa devre durumunun analizi araştırılmıştır. 7 trafo merkezi bulunan bir raylı sistem hattına ait veriler kullanılarak kısa devre durumunun olası etkileri grafikler üzerinden değerlendirilmiştir. Elde edilen sonuçlar üzerinden alınması gereken tedbirler verilmiştir.

Anahtar kelimeler: Algoritma, Demiryolu, Dinamik, Elektrifikasyon, Katener. 


\title{
Analysis of Catenary Short Circuit Case in a 1500 V DC Fed Railway Line with a Dynamic Model Algorithm
}

\begin{abstract}
Electricity supply railways in transportation systems have a high rate of investment preference. In the case of electric railways, the electrification of the electrification system is essential for the continuity of the operation. Before its design, the features of the system are simulated and the capacity, performance and failure conditions of the electrification system are tested. It is of utmost importance to analyze fault conditions and take possible measures for business continuity. In this study, having created a dynamic model, a $1500 \mathrm{~V}$ DC powered urban subway line has been simulated. While the algorithm developed for dynamic structure is explained, its simulation results are given. For the study, the analysis of a possible short circuit condition in the catenary system has been investigated. Using the data of a rail system line with 7 substations, the possible effects of the short circuit condition have been evaluated over the graphs. Measures to be taken from the results obtained are given.
\end{abstract}

Keywords: Algorithm, Railway, Dynamic, Electrification, Catenary.

\section{Giriş}

DC beslemeli demiryollarında yoğun olarak 1500 V DC besleme gerilimi tercih edilmektedir. Aracın tahriki için gerekli olan bu enerji TEİAŞ orta gerilim şebekesinden elde edilmektedir. Orta gerilim tarafindan temin edilen $34.5 \mathrm{kV}$ besleme gerilimi trafo merkezlerinde dönüştürücü transformatör ve redresör sistemi vasıtasıyla aracın kullandığı besleme gerilimine çevirilmektedir. DC beslemeli şehiriçi raylı sistemlerde iki istasyon arası mesafe yaklaşı 1-2 km civarında olmaktadır. Besleme merkezi arası mesafe ise besleme gerilimine bağlı olarak değişmekte olup 1500 V DC sistemlerde 1-4 km arasında olabilmektedir [1-6]. DC besleme demiryollarına ait eş değer devre şekil 1 ile gösterilmektedir. 


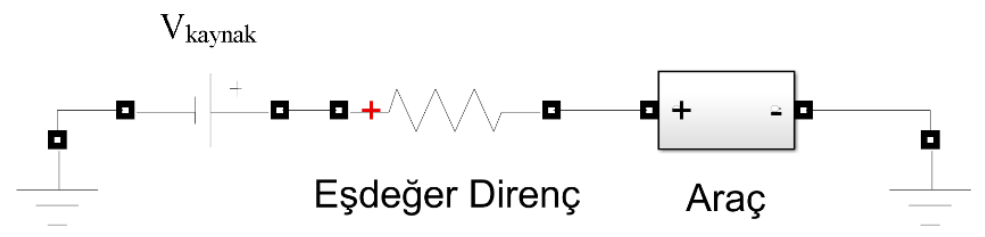

Ray

Ray

Şekil 1. DC Demiryoluna Ait Eşdeğer Devre Modeli

(1) eşitliği ile aracın geriliminin anlık olarak hesabı verilmektedir [1]. $V_{\text {araç }}$ araç gerilimini, $V_{\text {kaynak }}$ kaynak gerilimini, $I_{\text {araç }}$ araç gerilimini ifade etmektedir. R ile eş değer direnç gösterilmektedir. Kaynak gerilimi bu çalışmada 1500 V DC olarak alınmaktadır.

$V_{\text {arạ̧ }}=V_{\text {kaynak }}-\left(I_{\text {arạ̧ }} \times R_{\text {eşdeğer direnç }}\right)$

Aşağıda ray gerilimine ait eşitlikler (2) ve (3) ile verilmektedir [5]. $\mathrm{C}_{1}$ ve $\mathrm{C}_{2}$ katsayılar olup $\mathrm{V}_{(\mathrm{x})}$ ve $\mathrm{i}_{(\mathrm{x})}$ ile ray gerilimi ile ray akımı hesaplanmaktadır. $\mathrm{R}_{0}$ ray iletkeninin karakteristik direncini belirtmektedir.R ray direncini $\mathrm{R}_{\mathrm{G}}$ ise kaçak iletkenliği ifade etmektedir. Propogasyon sabiti $\gamma$ ile gösterilmiştir.

$$
\begin{aligned}
& V_{(x)}=-R_{0}\left(C_{1} e^{\gamma x}+C_{2} e^{-\gamma x}\right) \\
& R_{0}=\sqrt{\mathrm{R} R_{G}}
\end{aligned}
$$

Ray akımının hesabı ise (4) eşitliği ile verilmektedir [5].

$$
i_{(x)}=C_{1} e^{\gamma x}+C_{2} e^{-\gamma x}
$$


Akım; bara admitans matrisi Y ile gerilimin (V) çarpılması ile hesaplanmaktadır. Bu ifade (5)'de gösterilmektedir [17].

$$
\mathrm{I}=\mathrm{Y} \mathrm{V}
$$

Toplam güç eşitliği ise (6) ile verilmektedir [17]. $\mathrm{P}_{\mathrm{T}}$ gücü belirtirken, $\mathrm{V}$ ve I gerilimle akımı belirtmektedir.

$$
P_{T}=V_{T} \mathrm{I}_{T}
$$

Araca ait hareket denklemleri ise (7) ve (8) ile gösterilmektedir [10]. $\mathrm{V}_{(\mathrm{t})}$ ile $\mathrm{x}_{(\mathrm{t})}$ aracın hizı ile konumunu ifade etmektedir. İvme a ile belirtilirken $t$ ile zaman belirtilmektedir. $\mathrm{V}_{0}$ ve $\mathrm{x}_{0}$ ise ilk hiz ile ilk konumu ifade etmektedir.

$$
\begin{aligned}
& v_{(t)}=\mathrm{dx} / \mathrm{dt} \\
& x_{(t)}=\frac{1}{2} a t^{2}+v_{0} t+x_{0}
\end{aligned}
$$

$\mathrm{Bu}$ eşitlikler yardımıyla aracın hareket denklemi ve elektriksel tüketimi hesaplanmaktadır. Aracın ivmesiyle kütlesi çarpılarak araca etki eden toplam kuvvet hesaplanmaktadır. Aracın elektriksel tüketimi ise bu değerin aracın hızıyla çarpılmasıyla elde edilmektedir. Cer gücü sisteminin verimi ve cer besleme merkezlerinin sayısı arttıkça hattaki gerilim düşümü ile kayıplar azalmaktadır. Şekil 2 ile DC beslemeli bir demiryolunda DC gerilimin üretilmesine ait şematik verilmektedir. 


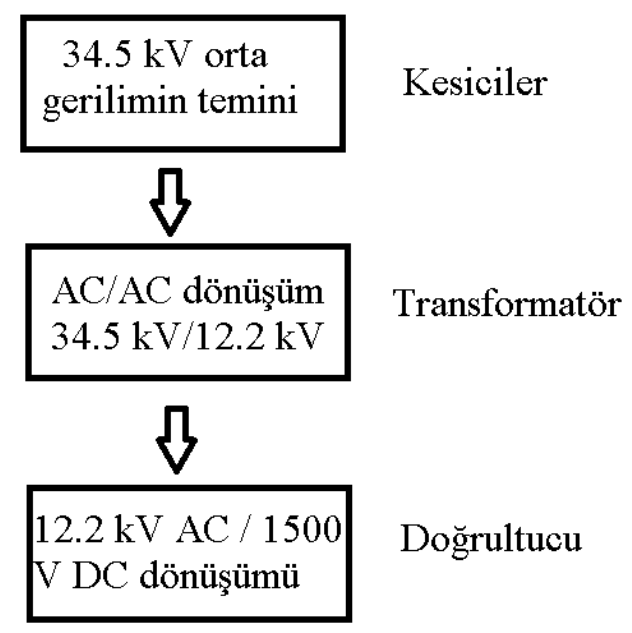

Şekil 2. DC Gerilimin Üretilmesi

DC beslemeli demiryollarında dalgalanma oranının azaltılması ve daha saf bir DC gerilim elde etmek için dönüştürücü transformatör çift sekonderli olarak tercih edilmektedir. Sekonder tarafta bulunan sarg1lar arasında ise 30 derece faz farkı bulunmaktadır. Cer sistemi trafo, doğrultucu ve bağlantı elemanlarından oluşmaktadır. Primer taraf üçgen sarg1 tipinden oluşurken sekonder taraf yıldız ve üçgen sarg1 tiplerinden oluşmaktadır. Demiryolu işletmesinde kesintisiz bir durum söz konusu olduğu için cer gücü sisteminde oluşabilecek bir trafo merkezi arızasında işletmede yaşanabilecek olası etkileri azaltmak için cer gücü birden fazla besleme noktasına sahiptir [7-11]. Raylı sistemlerde çok fazla dinamik değişkenin olması ve bu yapının sürekli kendini güncellemesi bu yük akışı probleminin çözümünü ve demiryolu benzetimini daha kompleks hale getirmektedir. DC sistemlerde optimal tasarım ve işletme için de benzetim çok önemlidir. Bu konuda farklı tasarımlar ile sistemlerin modellendiği çalışmalar bulunmaktadır. AC ve DC demiryollarının karşılaştırıldığı, FACTS (Esnek Alternatif Akım İletim Sistemleri) yöntemi ile demiryolu güç kalitesinin arttırılması, 
cer gücü için SVM (Destek Vektör Makinaları) yönteminin kullanılması yük akışı çalışmaları bulunmaktadır [12-16]. Çalışmaların büyük kısmının en önemli odak noktasını optimize sürüş teknikleri oluşturmaktadır [17]. Bu çalışmada ise oluşturulan yeni bir algoritma ile dinamik bir model kurgulanarak hatta oluşan bir kısa devre durumu gerçek veriler kullanılarak araştırılmıştır.

\section{Materyal ve Metod}

Bu çalışmada benzetim için yeni bir dinamik algoritma kullanılarak oluşturulan modeller ile raylı sistem kısa devre durumu modellenmiştir. Dinamik model Algoritması yardımıyla raylı sistem aracı, katener ve ray hatt1, elektriksel besleme hattı ve kısa devre durumu modellenmiştir. Bu çalışma için gerçek bir raylı sistem hattına ait parametreler kullanılmıştır. 1500 V DC besleme gerilimine ve 7 trafo merkezine sahip bir demiryolu hattı tercih edilmiştir. Benzetim için Matlab/Simulink programı kullanılmıştır.

\subsection{DC demiryolu simülasyon modeli}

DC beslemeli demiryolu katener modülü, ray modülü, orta gerilim transformatör modülü, DC redresör modülü, ara bağlantı modüllerinden oluşmaktadır. Örnekleme zamanı benzetim için gerekli olan hassasiyeti yakalamak için uygun ölçüde seçilmiştir. Bu değer sonuçlardan yola çıkılarak çeşitli denemelerden sonra elde edilmiştir. Şekil 3'de Matlab/Simulink benzetim ekranı gösterilmektedir. Benzetim için 7 trafo merkezine sahip, yaklaşı $12 \mathrm{~km}$ uzunluğa sahip 10 istasyondan oluşan bir hat kullanılmıştır. 


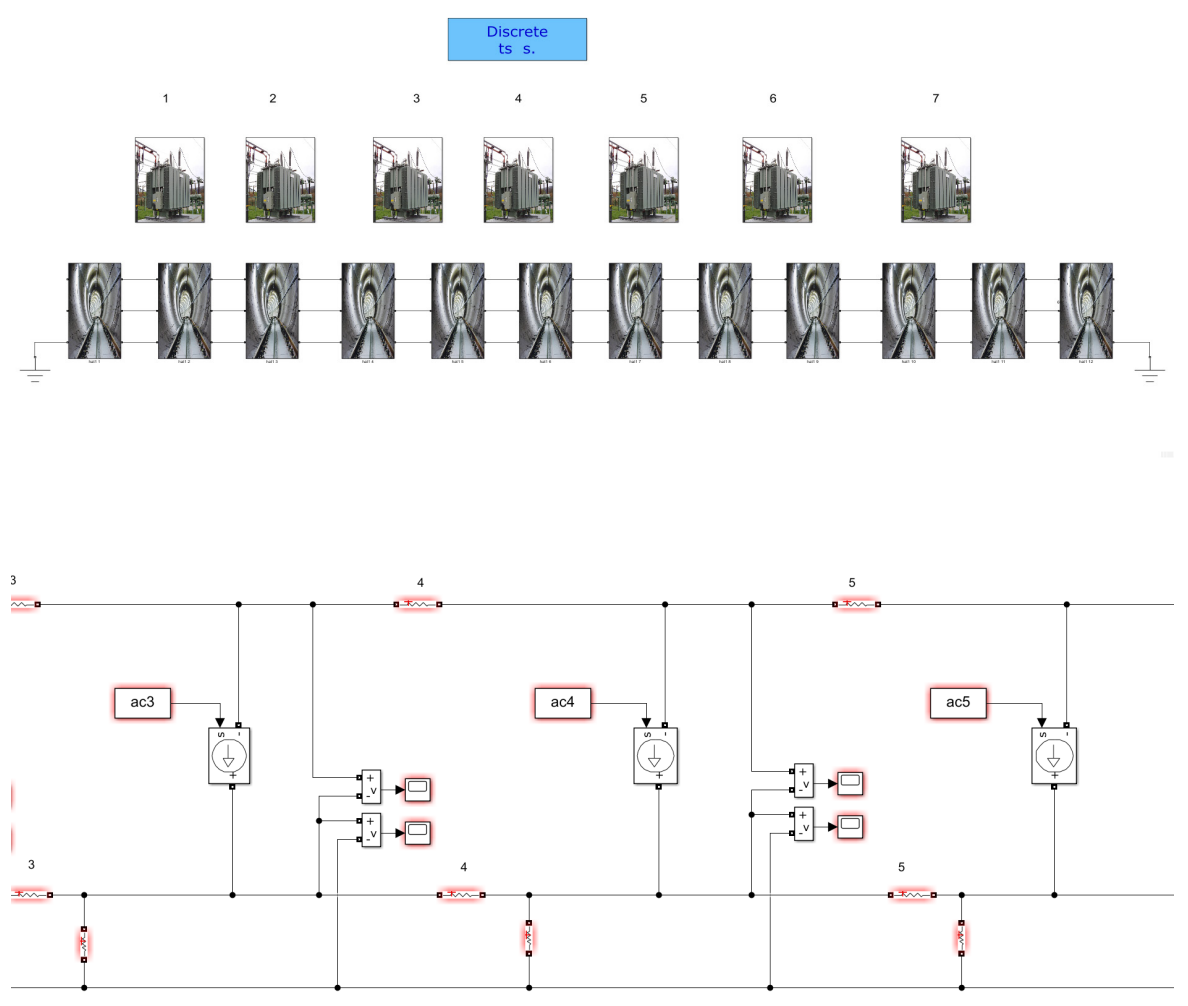

Şekil 3. DC Demiryolu Devresi ve Simülasyon Ekranı

İşletme sefer sıklığı fizibilite sonucu ortaya çıkan sonuca uygun olarak 180 saniye olarak alınmıştır. Benzetim için 12 adet raylı sistem aracı kullanılmıştır. İstasyonlar arası bekleme süresi 20 saniye alınmış olup simülasyon katenerde gerçekleşen kısa devre sonunda durdurulmuştur.

\subsubsection{Dinamik model algoritması}

Demiryolu işletmesinde değişkenlerin sürekli güncellenmesi ve değerlerin anlık olarak değişmesinden ötürü benzetim için dinamik bir 
model oluşturulması daha iyi sonuçların elde edilmesi için gereklidir. Şekil 4 ile dinamik modele ait algoritma verilmektedir.

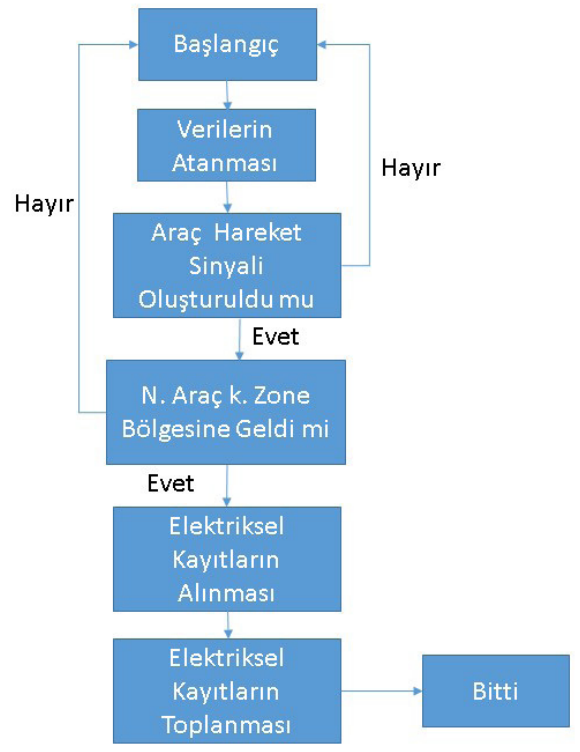

Şekil 4. Dinamik Simülasyon Algoritması

$\mathrm{Bu}$ algoritma her zone için tekrar edilerek benzetim çalıştırılır. Böylece demiryolu araç trafiği dinamik olarak modellenmektedir. Öncelikle sisteme ait işletmesel bilgilerin atanması ile adım 2'ye geçilmektedir. Daha sonra araç hareket sinyali oluşturularak araç için oluşturulan bölgeler arasında geçiş başlamaktadır. Her bir bölgeye ait kayıtlar alınarak elektriksel veriler elde edilmektedir. Bu çalışma tüm bölgeler için tamamlanıncaya kadar algoritma çalışmaya devam etmektedir. İşlem tamamlanınca simülasyon sona ermektedir.

\subsection{Katener kisa devre durumu}

Raylı sistemlerde katener hattının elektriksel sürekliliği işletme sürekliliği için esastır. Katener hattından meydana gelebilecek bir arıza 
durumu tren işletme operasyonunun kesintiye uğramasına neden olmaktadır. Katener sisteminde yaşanacak bir kısa devre durumu en sık rastlanan olayların başında gelmektedir. Elektriksel devrede iki farklı gerilime sahip noktanın birbirine temas etmesi sonucu devrede düşük bir empedans oluşumuna kısa devre denmektedir. Kısa devre IEC 909 standardında ayrıca tanımlanmaktadır. Kisa devre faz iletkenleri arasında, faz-toprak arasında, faz-nötr arasında meydana gelebilmektedir. K1sa devre akımına ait denklemi (9) ile verilmektedir. C katyasyı olup, $\mathrm{U}_{\mathrm{n}}$ faz-faz gerilimini ifade ederken $\mathrm{Z}_{\mathrm{k}}$ kısa devre empedansını göstermektedir. $\mathrm{I}_{\mathrm{k}}$ ile kısa devre akımı $\mathrm{S}_{\mathrm{k}}$ ile kısa devre gücü ifade edilmektedir.

$$
I_{k}=\frac{c U_{n}}{\sqrt{3} z_{k}}[\text { IEC 909] }
$$

Kısa devre gücü ise (10) ile gösterilmektedir.

$$
S_{k}=\sqrt{3} U_{n} I_{k}[\text { IEC 909] }
$$

$\mathrm{Bu}$ çalışmada katener ray arasında oluşabilecek bir kısa devre durumu analiz edilmiştir. Kısa devre süresi 1 saniye olup benzetim bu süre sonunda durdurulmaktadır. Kısa devre olayı hattın 5. ve 6 . km'leri arasında gerçekleşmektedir. Bu bölge 3. ve 4. trafo merkezlerinin besleme bölgesinde bulunmaktadır.

\section{Bulgular}

Katener kısa devre durumu için kısa devre akımı, hat gerilimi ve trafo merkezlerine ait benzetim sonuçları elde edilmiştir. Kısa devre durumunda meydana gelen değişimlere ait detaylı grafikler çıkarılmiştır. 


\subsection{Kısa devre akımına ait benzetim sonuçları}

Şekil 5 'de kısa devre bölgesinde kısa devre akımının değişimi zamana bağlı olarak verilmektedir. Görüldüğü üzere katenerden geçen akım kısa devre durumunun gerçekleştiği anda yükselmektedir.

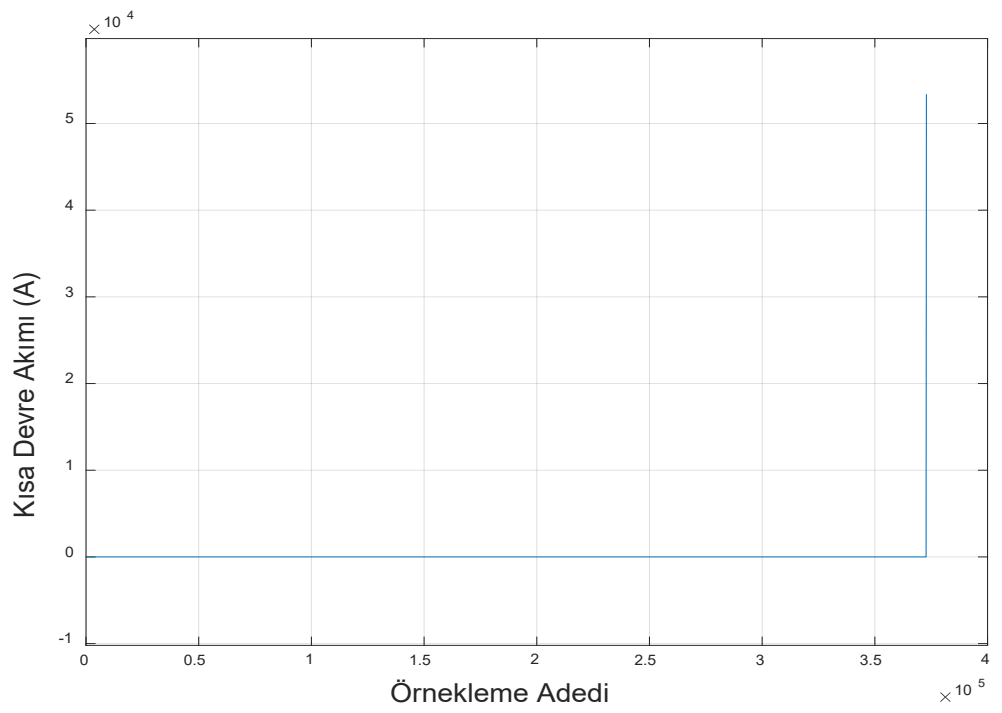

Şekil 5. Katener Kısa Devre Akımının Grafiği

Şekilde görüldüğ̈̈ üzere kısa devre anında kısa devre akımı 50 kA seviyelerine kadar yükselmektedir. Normal işletme durumunda katener hattından geçen akım 2 kA ile 6 kA arasında değişirken kısa devre anında bu akım çok yüksek mertebelere çıkmaktadır. 


\subsection{Hat gerilimine ait benzetim sonuçları}

Kısa devre durumunda hat geriliminde meydana gelen değişim ise şekil 6 ile gösterilmektedir.

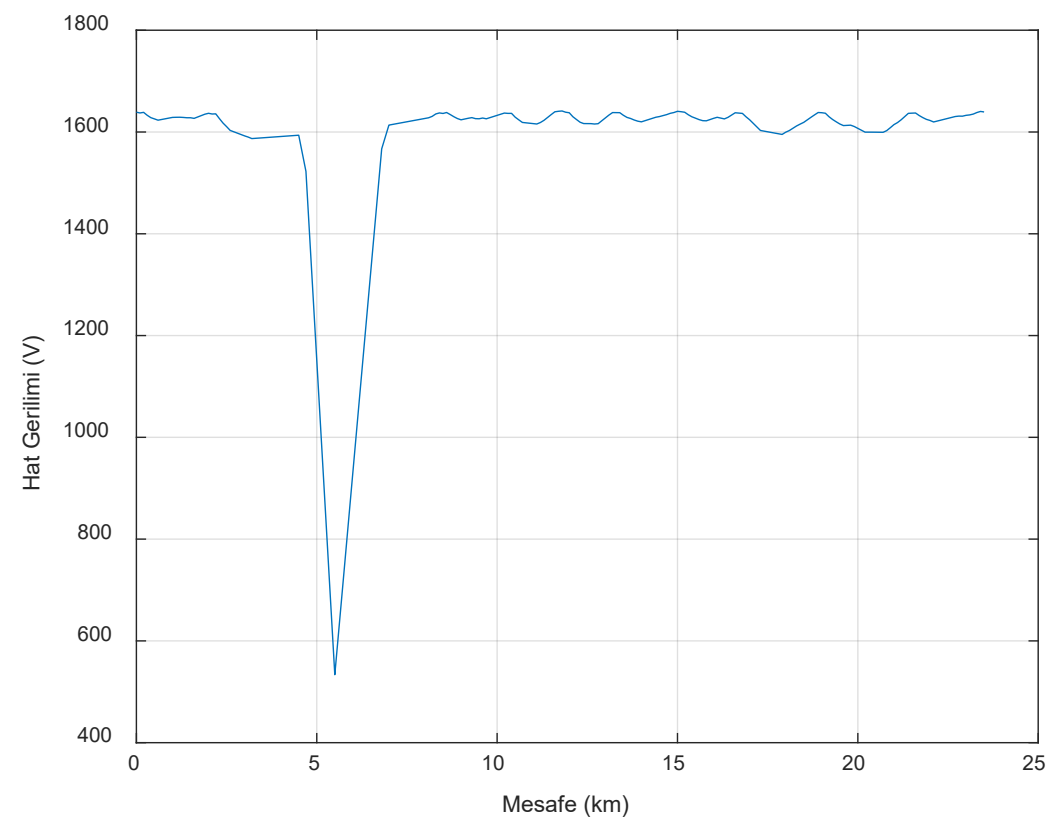

Şekil 6. Kısa Devre Durumunda Hat Geriliminin Değişimi

Nominal işletme durumunda $1600 \mathrm{~V}$ DC civarında olan işletme gerilimi kısa devre anında 500 V civarlarına kadar düşmektedir. Şekilde görüldüğü üzere gerilimin düşmesi kısa devrenin gerçekleştiği 5. ve 6. km'ler arasında gerçekleşmiştir. 


\subsection{Ray gerilimine ait benzetim sonuçları}

Şekil 7 ile ray gerilimine ait değerlerin mesafeye bağlı değişimi verilmektedir. Kısa devre durumunda katener gerilimi düşerken ray gerilimi bunun tersi karakteristikte davranarak yükselmiştir.

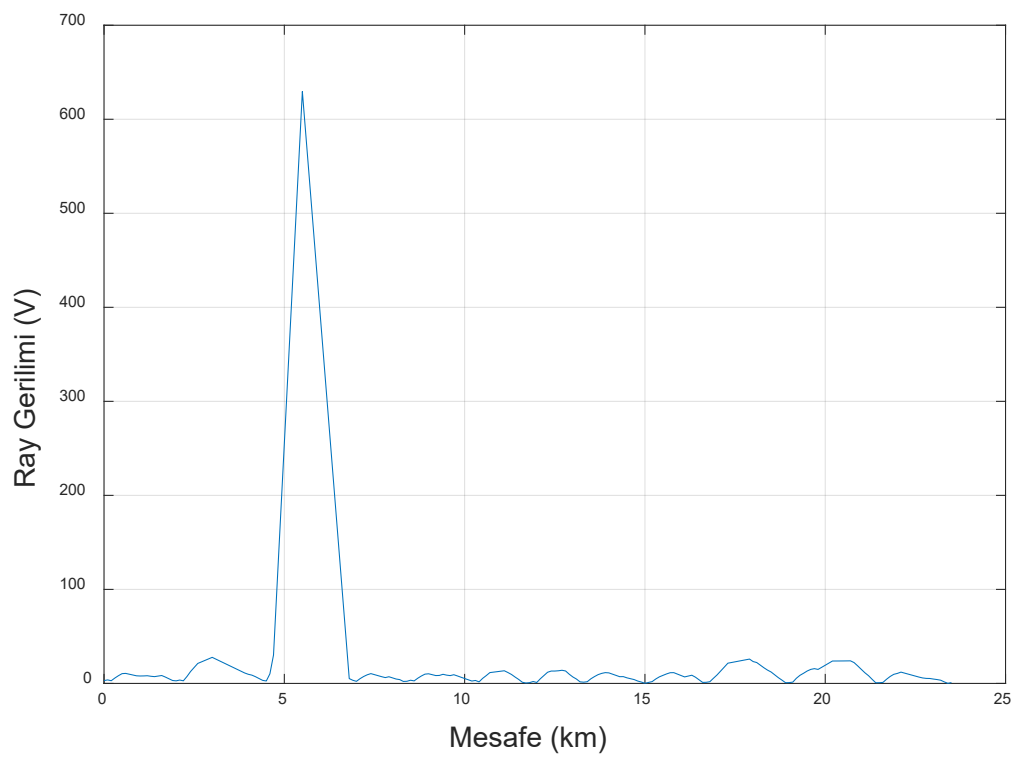

Şekil 7. Kısa Devre Durumunda Ray Geriliminin Değişimi

Görüldügüü üzere ray gerilimi 600 V DC seviyelerine ulaşarak şehiriçi raylı sistem hatlarında tehlikeli sayılacak bir değere ulaşmıştır. 


\subsection{Trafo merkezlerine ait benzetim sonuçları}

Kısa devre durumunda kısa devre bölgesini beslemekte olan 3. ve 4 . trafo merkezleri bu durumdan etkilenmektedir. Şekil 8 ve şekil 9 ile 3 . ve 4. trafo merkezlerinde çekilen akımda meydana gelen değişim gösterilmektedir.

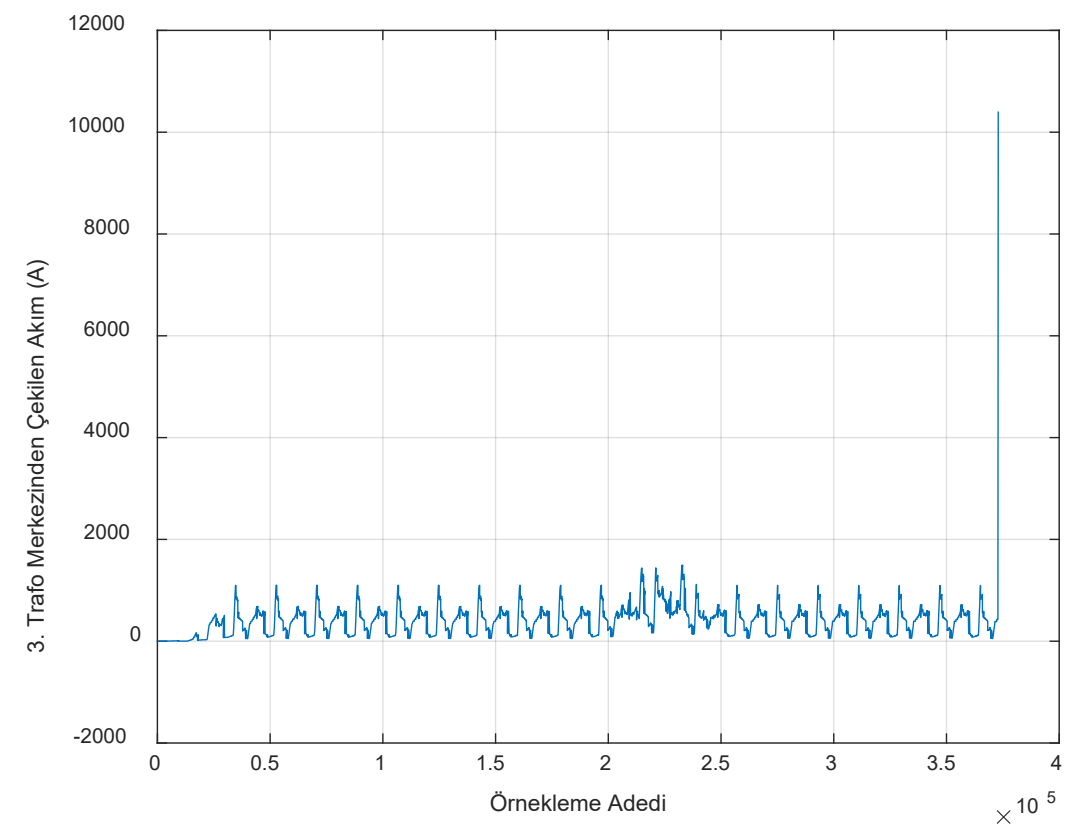

Şekil 8. 3. Trafo Merkezinden Çekilen Akımın Grafiği

3. trafo merkezinden çekilen akım anlık olarak $10 \mathrm{kA}$ seviyelerine kadar yükselmekte olup bu durum besleme trafosu için riskli bir durum oluşturmaktadır. 


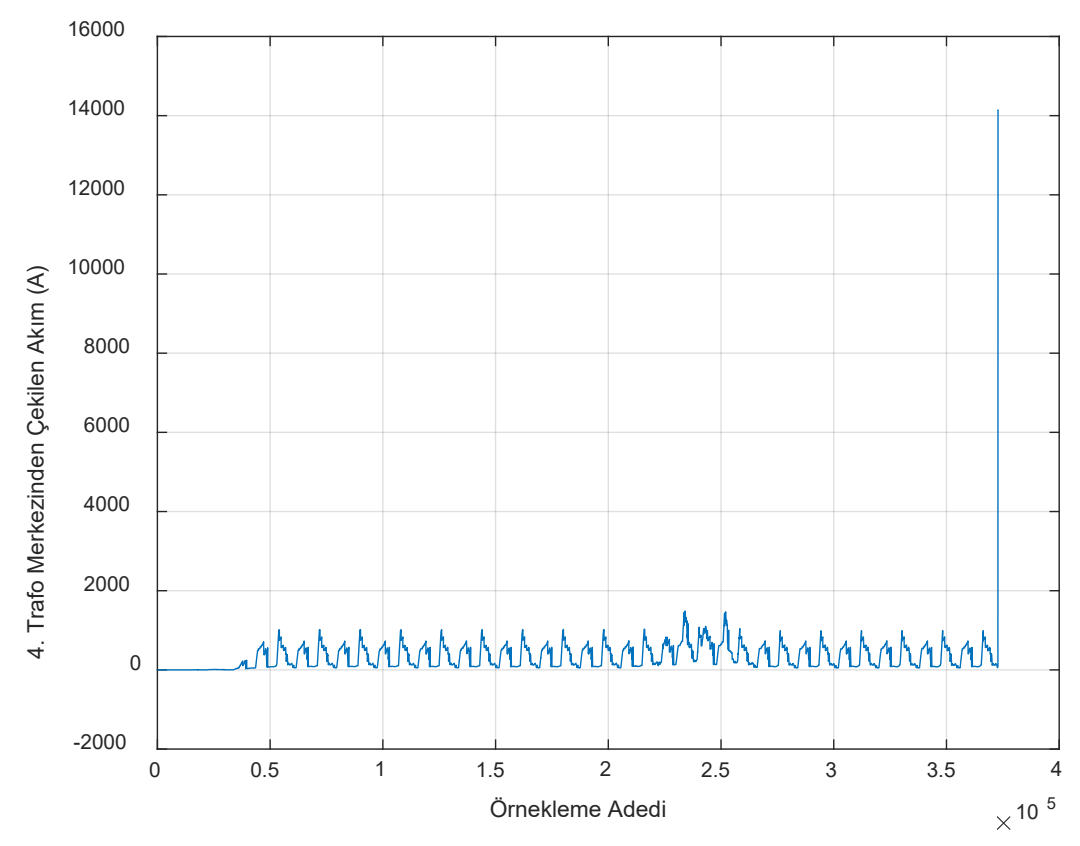

Şekil 9. 4. Trafo Merkezinden Çekilen Akımın Grafiğgi

4. trafo merkezinden çekilen akım ise kısa devre durumunda 14 kA seviyeleri kadar yükselmektedir. 3. ve 4. trafo merkezinden çekilen akımlar kısa devre durumunda yüksek mertebelere ulaşmaktadır.

\subsection{Sonuçlarının karşılaştırılması}

Benzetim sonuçları ile ilgili özet tablo ve öneriler tablo 1 ile verilmektedir. EN50122 ile EN50163 demiryollarında besleme gerilimleri ve ray dokunma gerilimleri ile ilgili standartlar olup ilgili voltaj limitlerini ifade etmektedir. 
Tablo 1. Benzetim Sonuçlarıyla İlgili Özet ve Öneriler

\begin{tabular}{|c|c|c|c|}
\hline Benzetim & $\begin{array}{l}\text { Max ve Min } \\
\text { Değerler }\end{array}$ & Risk & Öneri \\
\hline $\begin{array}{l}\text { Max Katener Kısa } \\
\text { Devre Akımı (kA) }\end{array}$ & $50 \mathrm{kA}$ & Limit Üstü & $\begin{array}{l}\text { İlgili Bölge Korumaya } \\
\text { Alınmalıdır }\end{array}$ \\
\hline $\begin{array}{l}\text { Min Hat Gerilimi } \\
\text { (V DC) }\end{array}$ & $500 \mathrm{~V} \mathrm{DC}$ & $\begin{array}{l}\text { EN } 50163 \\
\text { Limitlerinin } \\
\text { Dişında }\end{array}$ & Araç trafiği durdurulmalıdır \\
\hline $\begin{array}{l}\text { Max Ray Gerilimi } \\
\text { (V DC) }\end{array}$ & $600 \mathrm{~V} \mathrm{DC}$ & $\begin{array}{l}\text { EN } 50122 \\
\text { Limitlerinin } \\
\text { Dişında }\end{array}$ & $\begin{array}{l}\text { Ray Bölgesine Herhangi Bir } \\
\text { Unsurun Girmesi Engellenmelidir }\end{array}$ \\
\hline $\begin{array}{l}\text { Max 3. Trafo } \\
\text { Merkezi (kA) }\end{array}$ & $10 \mathrm{kA}$ & $\begin{array}{l}\text { Nominal } \\
\text { Durumun Çok } \\
\text { üstünde }\end{array}$ & $\begin{array}{l}\text { İlgili Trafo Merkezinin Devre } \\
\text { Kesicisi Kontrol Edilmelidir }\end{array}$ \\
\hline $\begin{array}{l}\text { Max 4. Trafo } \\
\text { Merkezi (kA) }\end{array}$ & $14 \mathrm{kA}$ & $\begin{array}{l}\text { Nominal } \\
\text { Durumun Çok } \\
\text { Üzerinde }\end{array}$ & $\begin{array}{l}\text { İlgili Trafo Merkezinin Devre } \\
\text { Kesicisi Kontrol Edilmelidir }\end{array}$ \\
\hline
\end{tabular}

[1] ile verilen çalışmada AC beslemeli bir demiryolu hattına ait cer simülasyonu yapılarak farklı işletme senaryolarına ait elektriksel durum analiz edilmiştir. Cer merkezleri arası mesafenin yapay zeka teknikleri ile belirlenmesi [2] ile yapılmıştır. [3] ve [4] ile verilen çalışmalarda hattan elde edilen verilerle aracın oluşturduğu gerilim düşümü yapay zeka teknikleri kullanılarak hesaplanmıştır. [5] ile topraklama sisteminin kaçak akımlara olan etkisi araştırılmıştır. Tüm bu çalışmaların ortak özelliği DC raylı sistem hattının simüle edilerek sonuçların elde edilmesidir. Bu çalışmada ise raylı sistem hattına ait kısa devre durumu ve olası etkileri araştııılmıştır. Çalışma kapmasında kısa devre durumunun hem katener hattına hem de ray hattına olası etkileri analiz edilmiştir. Tüm bu özelliklerden dolayı bu çalışma önceki çalışmalardan ayrılmaktadır. [8]'de ise AC beslemeli bir raylı sistem hattına ait güç akış analizi yapılarak sonuçlar elde edilmiştir. 


\section{Tartışma ve Sonuç}

Bu çalışmada DC beslemeli bir demiryolu benzetimi için yeni bir algoritma yardımıyla dinamik bir model oluşturularak katener kısa devre durumu analiz edilmiştir. Çalışma için 1500 V DC beslemeli bir raylı sistem hattı tercih edilerek olası durum için bir takım tavsiyelerde bulunulmuştur. Katener hattında gerçekleşecek bir kısa devre durumunda kısa devre akımı 50 kA mertebelerinde olmaktadır. Hat gerilimi ise 500 V DC seviyelerine kadar düştüğü için EN 50163 limitlerinin dışında kaldığı için bu durum işletme trafiğininin aksamasına neden olmaktadır. Ray geriliminde ise gerilim yükselmesi gibi tersi bir durum oluşmasına rağmen dokunma gerilimi ile ilgili problem ortaya çıkmaktadır. Bu durumda EN 50122 standardının limitleri dışına çıkılmaktadır. Kisa devre mahalini besleyen iki trafo olan 3. ve 4. trafo merkezlerinde ise besleme akımı anlık olarak $10 \mathrm{kA}$ ile $14 \mathrm{kA}$ seviyelerine kadar yükselmektedir. Katener ray arası kısa devre durumu raylı sistem hattı için riskli bir durum ortaya çıkarmakta olup tablo 1'de tavsiye edilen öneriler ışığında bu durum kontrol altına alınmalıdır. Çalışmada kullanılan algoritma ile olası kısa devre durumlarına karşı oluşacak durumlar analiz edilmiştir. Geliştirilen bu yeni algoritma ile sistem bölgelere ayırılarak elektriksel kayıtlar tutulmaktadır. Bu sayede sistem bölgesel ve bütüncül olarak analiz edilerek olası durumların tespiti daha sağlıklı bir şekilde yapılmaktadır. Bu yeni algoritma ile sistemin analizi daha hızlı ve verimli bir şekilde yapılmaktadır. Yeni yapılan hatların sayısı arttıkça ve mevcut hatların uzunluğu arttıkça bu hatların güvenli olarak işletilebilmesi olası durumlarda bir takım önlemlerin alınmasını zorunlu kılmaktadır. Bunlar selektiviteli akıllı röle koruma sistemlerinin güç sistemine kurulması, parafudr kullanımı, araç işletmesinin sınırlandırılması gibi işletmesel önlemlerdir. 


\section{Kaynaklar}

[1] Kocaarslan, İ., Akçay, M., T., Ulusoy, S., E., Bal, E., Tiryaki, H. Creation of a dynamic model of the electrification and traction power system of a $25 \mathrm{kV}$ $\mathrm{AC}$ feed railway line together with the analysis of different operation scenarios using Matlab/Simulink, Turkish Journal of Electrical Engineering \& Computer Sciences, 25, (2017), 4254-4267.

[2] Akçay, M., T., Kocaarslan, İ. Determination Of Distance Between DC Traction Power Centers İn A 1500 V DC Subway Line With Artificial İntelligence Methods, Turkish Journal of Electrical Engineering \& Computer Sciences, 27, (2019), 289-303.

[3] Kocaarslan, İ., Akçay, M., T., Akgündoğdu, A., Tiryaki, H. The comparison of the ANN and SVM Methods for the Prediction of Voltage Drop on a Subway Line, International Journal of Engineering Research and Advanced Development (IJERAD), 10, (2017), 57-65.

[4] Kocaarslan, İ., Akçay, M., T., Akgündoğdu, A., Tiryaki, H. The comparison of the ANN and ANFIS methods for the prediction of voltage drop on an electric railway line, Journal of Electrical \& Electronics Engineering (IUJEEE), 18, (2017), 26-35.

[5] Alamuti, M., M., Nouri, H., Jamali, S., Effects of earthing systems on stray current for corrosion and safety behaviour in practicalmetro systems, IET Electr. Syst. Transp., 1, (2011), 69-79.

[6] Brenna M, Foiadelli F., The compatibility between DC and AC supply of the Italian railway system, Power and Energy Society General Meeting, (s. 1-7), (2011,July) San Diego, USA.

[7] Abrahamsson L, Kjellqvist T, Ostlund S. High-voltage DC-feeder solution for electric railways. IET Power Electronics, 5, (2012), 1776 - 1784.

[8] Raygani SV, Tahavorgar A, Fazel SS, Moaveni B. Load flow analysis and future development study for an AC electric railway, IET Electrical Systems in Transportation 2, (2012), 139-147.

[9] Goodman C.,J., Chymera, M., Modelling and simulation, REIS 2013 Railway Electrification Infrastructure and Systems Conference, (s. 16-25), (2013, June), London, England.

[10] Calderaro, V., Galdi, V., Graber, G., Piccolo, A. Energy Management of Auxiliary Battery Substation Supporting High-Speed Train on $3 \mathrm{kV}$ DC Systems, 4th International Conference on Renewable Energy Research and Applications, (2015, Nov), 1224-1229, Palermo, Italy. 
[11] Shin HS, Cho SM, Kim JC. Protection scheme using SFCL for electric railways with automatic power changeover switch system, IEEE Transactions on Applied Superconductivity, 20, (2012), 5600604.

[12] Shin HS, Cho SM, Huh JS, Kim JC, Kweon DJ. Application on of SFCL in automatic power changeover switch system of electric railways, IEEE Transactions on Applied Superconductivity, 22, (2012), 5600704.

[13] Kolar, V., Hrbac, R., Mlcak, T., Measurement and simulation of stray currents caused by AC railway traction, EPE 2015 Electric Power Engineering Conference, (s. 764-768), (2015, May), Prag, Czech Republic.

[14] Chen, M., Jiang, W., Luo, J., Wen, T, Modelling and simulation of new traction power supply system in electrified railway, ITSC 2015 IEEE 18th International Conference on Intelligent Transportation Systems, (s. 1345-1350), (2015, September) Las Palmas, Canada.

[15] Soler M, Lopez J, Manuel J, Pedro MS, Maroto J. Methodology for multiobjective optimization of the AC railway power supply system, IEEE Transactions on Intelligent Transportation Systems, 16, (2015), 2531-2542.

[16] He Z, Zhang Y, Gao S. Harmonic resonance assessment to traction power supply system considering train model in China high-speed railway, IEEE Transactions On Power Delivery, 29, (2014), 1735-1743.

[17] Tian, Z., Hillmansen, S., Roberts, C., Weston, P., Chen, L., Zhao, N., Su, S., Xin, T., Modeling and Simulation of DC Rail Traction Systems for Energy Saving, (s. 2354-2359), (2014, October), Qingdao, China. 